sip the milk from a ladle. A spoon is frequently used, the only cleansing it receives being on the visit to the mouth between cans. Licking the under part of the stopper is a practice generally followed, the stopper being then thrown into a box, the mixed milk drawn off into the emptied cans, and the dirty stoppers again inserted. It is said that one milkman arranges his cans in a row, removes the stoppers, inserts a finger with great dexterity into each can and thence to his mouth in rotation. In one place, the largest cans are tasted by dipping in the hand instead of a ladle. It is easy to see how a taster with diphtheria in his throat, or typhoid on his hands, might infect a whole community. So long as these methods are allowed, only healthy men should be permitted to taste milk, but the methods should be changed. In want of a better device, a supply of common wooden tongue depressors would do, carried in a double box; the clean on one side, the used on the other. These could be bought at a trifling cost and easily cleansed. One man has suggested the use of paraffine straws. Most of the tasters spit also. To see tasters spitting the milk from the mouth in the midst of the open cans, even though care is taken not to spit into the same, is not an agreeable spectacle for the prospective consumer.

Pasteurization is carried on by but few Boston contractors, and even by them not for their whole supply. The milk is in the pasteurizing machine about four minutes, and passes through three processes. First, it is heated to about $165^{\circ} \mathrm{F}$., then cooled by ice water, and finally cooled by brine. Milk keeps much longer after this process because most of the bacteria are thus destroyed. However, a milk kept sweet by cleanliness and cold is much to be preferred to a pasteurized supply filled with lifeless organisms and their byproducts. One contractor wishing to show what interest he took in furnishing a bacteria-free supply of milk to his patrons showed a report from a bacteriologist stating that the milk before going through the pasteurizing process at his plant in a distant town contained $7,000,000$ bacteria per cc.; after the process but 4,000 . Consider for a moment the condition this milk was allowed to reach before pasteurization was used to prevent further development.

The milk can may be held responsible for many high counts. Some milk cans, each time the milk is emptied from them, are thoroughly cleansed and sterilized before being sent back to the producer, but as a rule this is not true. Such a can usually has the following history: purchased new it is kept for a while on the car for family trade and is carefully attended to, but as age advances it gives way to brighter and better looking cans, and takes its place among the store cans. The farmer cleans it with hot water as best he can. He does not mind the dents in the side, for the dented can holds less milk. When the can is filled with warm milk, the bacteria lodged in inequalities, broken seams, etc., multiply rapidly, the spring water in which the can is usually set not cooling the milk sufficiently to prevent bacterial growth. After the early morning ride to the stations and a wait on the station platform, the milk is cooled in the car on its journey to the contractor, where it arrives say about 10 A.M. If still sweet, to the taster's tongue, the milk is poured into the mixer, and the empty uncleaned can filled with the mixed milk and stored in ice until early the following morning, when it is delivered to the storekeeper. He disposes of the milk during the day, returns the empty dirty can the following morning to the contractor, who, without cleaning, ships it to the farmer and the round begins again. To furnish clean milk, some contractors have two lines of cans - one for the farmer sent back the morning it is received and reaching him with what milk is left in it perfectly clean and sweet; the other set receiving the mixed milk and being sent to the customers. These cans are carefully cleansed and sterilized each time they return. The contractor finds but little sour milk when the cans are thus cared for, and the inspector finds but few bacteria.

The milk can stopper deserves a few words in passing; being generally of wood, it absorbs the milk sooner or later into its pores, becomes filled with bacteria, and if not properly cleansed with boiling water each time it is used, readily infects the fresh milk. Split one of these old stoppers and you will see how the milk has penetrated the pores of the wood. The wooden stopper fits the can tightly, and if properly cleansed has no superior while sound, but the places where it is properly cleansed are few. Metal stoppers of the same material as the cans are now used to some extent. This is a step in the right direction.

Some of the contractors seem anxious to do what they can to furnish a pure milk supply. Dairymen are learning the two C's - Cleanliness and Cold. The outlook is favorable. We expect the time will soon come when it will be difficult to find amongst Boston milk dealers milk containing more than 500,000 bacteria per cc.

\section{ISOLATION METHODS AND PRECAUTIONS IN CONTAGIOUS DISEASE.*}

BY F. P. DENNY, M.D., BROOKLINE, MASS., Assistant in Clinical Medicine, Harvard Medical School, Bacteriologist of the Brookline Board of Health.

Texтвоoks and the instruction received in the medical school seem to help us but little when we have our first practical experience in the isolation of a case of contagious disease. With varying degrees of knowledge of the principles involved, each physician works out for himself some of the details of isolation, and as a result our methods vary a great deal. Dr. A lays great stress on taking certain precautions which Dr. B, an equally good man, neglects; on the other hand, Dr. B carries out some measures which Dr. A considers unnecessary. The laity are quick to recognize these differences in our practice, as they are much more apparent than differences in therapeutic methods, and by this

* Read at a meeting of the Norfolk District Medical Society, $*$ Read at
Jan. 26,1904 . 
lack of uniformity we often injure each other and the good name of the profession.

It has seemed, therefore, that it might be profitable for us to spend an evening discussing and comparing methods, suggesting to each other ways in which infection may be spread from a contagious case and the precautions that should be taken. What I have to say is in the nature of an introduction to such a discussion. It is hoped that it will serve to remind you of other and better methods which you yourselves are in the habit of employing and of which you will give us the benefit in the discussion to follow.

In considering what precautions to take in a th contagious disease we must always keep in mind the nature of the infectious agent and the manner in which it is disseminated.

Diphtheria. - The Klebs-Lœffler bacilli are given off chiefly in the secrctions of the nose and throat. These secretions are very profuse, as a rule, in the acute stage, and we often see patients with profuse discharges from the nose, and drooling from the mouth out over the pillow. They are apt to cough a good deal and in so doing spray the secretions to a considerable distance from them. The number of bacilli given off from some of these cases is very great, and the immediate surroundings of the patient must become very thoroughly infected. In a bit of diphtheritic membrane the bacilli may live a long time (several months), but when the bacilli are in a thin layer exposed to light and dryness they lose their virulence much sooner. According to good authorities, before the secretions can have become sufficiently dried and pulverized to float as dust in the air, the bacilli will probably have lost their virulence, so that there is comparatively little danger of the aerial transmission of the bacilli to other parts of the house. Our precautions, therefore, should be chiefly taken to guard against the infection being carried out by persons leaving the room or on objects taken out.

Scarlet Fever. - We know much less about the nature of the infectious agent in this disease. Dr. Mallory has recently found protozoan-like bodies in the skin of four cases, to which he has given the name cyclaster scarletinalis. ${ }^{1}$ Whatever the relation of these bodies may prove to be, clinical cbservation has shown beyond much question that the infection is in the secretions from the nose, throat and ear, in the epidermis, and probably also in the urine and feces. The infection is more persistent than in diphtheria and seems to stick longer to rooms and objects; hence it is more important to limit the dissemination of the infectious material.

It is generally thought that scarlet fever is much more contagious than diphtheria on account of the scales of epidermis which are supposed to fly about through the air during convalescence. To how great an extent this takes place it is impossible to say, but the disease does not seem to be as contagious as it would be if this took place to any considerable extent. It was found

' Journal Medical Research, January, 1904. on investigation that there was no increase in the number of cases of scarlet fever in the immediate vicinity of the South Department of the Boston City Hospital. ${ }^{2}$ Personally I believe that the danger of the aerial transmission of scarlet fever has been overestimated.

Mixed infections. - Associated with the KlebisLœffler bacilli in diphtheria there is often also an infection with other bacteria, the most important of which are the streptococci; and in scarlet fever it is the rule to have a mixed infection with the streptococci. One object of isolation in these diseases may be to guard against the dissemination of these pyogenic bacteria, especially if there are surgical or puerperal cases about, and the personal precautions which the physician takes in visiting a contagious case should not only have as their object to guard against carrying away the specific organisms of the disease, but also to avoid transmitting the streptococci.

\section{ISOLATION METHODS.}

I shall consider isolation methods only in diphtheria and scarlet fever, the two diseases in which we most often wish to carry out strict jsolation at home.

As soon as the diagnosis of these diseases is even suspected, certain precautions should be taken at once: The patient should be confined to one room, from which all susceptible persons are excluded, and all eating utensils, handkerchiefs, towels, etc., should be boiled after use. These precautions should be taken in every case of sore throat in a household where there are children.

When the diagnosis has been confirmed there are many things to be arranged for by the physician. There is the room to be selected and prepared, the nurse to be engaged, and if it is diphtheria, antitoxin must be given to the patient and to each member of the household. The domestic and social plans of the family have to be suddenly changed and there are innumerable questions arising which the physician is called upon to decide. The establishment of a proper quarantine in a private house is a very time-consuming affair, but it is time well spent; it saves a great deal of trouble and annoyance later, and makes the subsequent care of the case much more satisfactory.

The selection, preparation and care of the patient's room should next be considered, but as these important details are more often described in textbooks, I shall pass them over here and merely say that, in the selection of the room the most important factors to be considered are, remoteness, the presence of sunlight and the location of the bathroom. One cannot have a satisfactory strict quarantine unless there is a bathroom for the exclusive use of the nurse and patient. If possible there should be a room for the nurse adjoining the patient's room. The ideal conditions are to have the two bedrooms and bath all connecting, but a satisfactory ar- 
rangement also is to have the three rooms at one end of a hall. In the bathroom there should be a small gas stove or some other arrangement for th heating a boiler in which articles may be sterilized.

It is a practice with many nurses to hang a sheet across the door of the patient's room, which may or may not be kept wet with a disinfectant. Personally I do not think this sheet accomplishes much, because, as already stated, there is probably slight danger of the aerial transmission of these two diseases. Currents of air which might blow infected particles of lint or epidemis along the floor will also blow up the sheet. If used at all the sheet should be long and weighted with a sandbag or something of the sort.

Dr. Harrington ${ }^{3}$ has called attention to the strong currents of air which often blow under a closed door, and suggests that a sandbag should be placed along the sill to prevent this.

Across the hall, just outside the sheet (if one is used), or outside the door of the patient's room, there should be drawn a chalk line or an imaginary line to represent what may be called " the neutral line," which is never to be crossed by those in the household outside the quarantine and by the nurse only after she has taken special precautions. At this neutral line there should be a small table, preferably with a large tin waiter on it.

After quarantine is once established there must necessarily be an exchange of certain articles with the rest of the house, and whatever is to go out of the room must be put on the table in a sterile condition. In a short personal experience in being quarantined at home I found that the articles which have to go out of the room may be divided into four classes: (1) Soiled clothes for the laundry; (2) dishes, eating utensils, etc.; (3) food refuse; (4) combustible waste.

Soiled clothing for the laundry may be boiled and then the whole boiler is put on the table at the neutral point. When the water has cooled those outside take the clothing out, being careful not to touch the handles of the boiler by which the nurse had lifted it. Another method is to have the clothing done up in sheets wet in corrosive sublimate or carbolic acid, and then carried to the laundry where it is immediately put into boiling water. The immediate boiling of clothing has the disadvantage that it fixes stains in the clothes so that they will not wash out. This may be avoided by soaking them first for two hours in a cold solution of carbolic acid, 3 parts; soft soap, 2 parts; cold water, 100 parts.

Most of the dishes and eating utensils used by the patient should be kept in the room, but it is often desirable to send back some of the dishes, especially those on which the food is served. These should be boiled and then put on the table while in the boiler, just as described above for clothes.

All the really soft food refuse may be put into the watercloset, while the solid part may be done

3 Boston Mid. and Sura. Journ., CXLI, No. 25, 1899, p. 617. For the subject of "Disinfection in the Sick Room" the reader is also referred to this article of Dr. Harrington's. up in newspapers and disposed of with the combustible waste; or all the food refuse may be thrown into a covered receptacle containing chloride of lime, which is emptied daily.

The combustible waste consists chiefly of papers, rags, etc., which can be burned in the open fire if there is one, or it may be done up carefully in several layers of newspaper by the nurse who puts the package on top of another fresh paper which has been spread on the top of the table by some one outside of quarantine. The person outside then wraps up the bundle in the fresh newspaper without touching the nurse's package and the whole may then be taken down to the furnace or kitchen stove and burned.

Exercise for the nurse. - The nurse should have an opportunity to get out of doors every day. This is easily arranged if there are two of them, but with only one it is difficult, especially if the patient is a very small child. Sometimes if a member of the family will stay just outside the room the child will be satisfied and remain quiet for the hour that the nurse is away. Before going out the nurse should change her dress, wash and disinfect her hands, and put on overshoes while passing through the house.

PRECAUTIONS TO BE TAKEN BY THE PHYSICIAN IN VISITING A CASE OF CONTAGIOUS DISEASE.

There is some danger of the transmission of these diseases by a third person, but it is probably not very great. A great responsibility rests upon us, however, to take every reasonable precaution to reduce the danger to a minimum. For the sake of brevity I have written out some of the precautions in the form of rules. Most of them seem too simple and self-evident to mention here, but all of them are points which I have either found myself neglecting or seen others neglect.

(1) While making a visit do not sit down or lean up against anything. It should be possible to make a visit without coming in contact with anything except with the hands in examining the patient and with the soles of the shoes on the floor.

(2) After having touched the patient or objects in the room remember that anything that the hands touch will in turn be infected; for example, do not put the hands in the pocket to take out watch, pencil, or thermometer, and do not go to the bag to get out the stethoscope, corrosive tablets or drugs without first disinfecting the hands. In visiting any patient for the first time, where it is known that there is a rash or a sore throat, it is a good rule always to get out the corrosive tablets from the bag before going near the patient.

(3) In examining the throat stand so that it is possible to step to one side if the patient coughs or gags. In difficult cases this cannot be done.

(4) At the end of the visit disinfect the hands; do not first wash them in a small amount of water, as this may serve to wash some of the organisms from the smooth surface of the skin to the under surface of the nails, where the disinfectant will not readily reach them. It is better to first rinse 
the hands in a stream of running water or immerse at once in the disinfectant.

(5) Do not use any towel which the nurse has handled or which might have become infected in any way. If there is no towel that can be trusted let the hands dry in the air.

(6) In going out do not touch any door handle which could have been infected.

Each one needs to watch himself carefully during a visit in order to avoid making mistakes; even then we shall make some; but if we are only conscious of our mistakes, if we know when we have come in contact with infected objects, or when the patient has coughed on us, then it is easy to guard against carrying the infection to others.

It is especially important that we physicians should set a good example in taking precautions; for if we are careless during the short period of our visits it cannot be expected that the nurse and others will keep up their precautions day in and day out during the long weeks of quarantine.

A cotton gown or long coat may be worn in visiting a contagious case and is often a great protection, especially where difficult throat examinations have to be made. Unless a gown is properly cared for it may be worse than useless. The ideal way is to have the gown sterilized each time after use, and when this is not done it should be hung carefully so that the inner surface cannot come in contact with the infected outer surface. I remember once visiting a contagious hospital in order to see the building and was given a gown to put on which was taken out of a wardrobe in which there were four or five other gowns all bunched up together. For the sake of politeness I put on the gown although I felt there was more danger of getting infected from the gown than from the air of the ward.

Disinfection of the physician's clothing, etc. If we have reason to believe that our clothes have been infected we should do something more than give them a rest of twenty-four hours. They may be disinfected with formaldehyde gas in a small closet or cabinet, or they may be hung out in the sun and their position frequently changed so that all infected surfaces will be exposed to the direct rays of the sun. The direct sunlight has a very rapid action and is one of the most convenient and reliable disinfectants that we have. We are apt, however, to overestimate the efficiency of simple airing without the direct sunlight, and trust too much, for example, to a walk in the open air to get infection out of our clothing. If our clothes have been infected from organisms floating as dust in the air of the room,a very remote possibility, I believe,- - then currents of air are doubtless efficient to remove a large part of such infection. If, however, the clothing has been infected by minute particles of secretion sprayed out by the patient, or by contact with infected objects, then currents of air will have little effect.

We should be very careful not to get the inside of our gloves infected. The moisture of the hand and the absence of light furnish conditions favorable to the long life of pathogenic organisms.

It is sometimes desirable (and often a great satisfaction) to be able to disinfect with formaldehyde gas such small articles as gloves, stethescope, or the whole bag and its contents. The following device which I have found very convenient and efficient can be arranged by any physician in a few minutes. An ordinary tin cracker box of suitable size is raised up on four small bottles, or other objects, so that an alcohol lamp or gas flame can be put beneath. On the bottom of the box at one corner a formaldehyde pastile is put and close to it a piece of moist sponge or some wet cotton. The objects to be sterilized should be put into the box so that all infected surfaces are exposed to the gas and without touching the bottom of the box near the pastile. The box cover being closed and sealed with adhesive plaster, the lamp is lighted. The flame should be very small ( $\frac{1}{2}$ to 1 inch), and should be directly beneath the pastile. After fifteen minutes the pastile will be volatilized and the lamp may be removed, but the box should stand sealed for at least two hours. The usual method of volatilizing the pastile with the lamp inside the box has the disadvantage that the lamp sometimes goes out on account of deficient oxygen and by that method also the air is drier. In this method the moist sponge or cotton being heated by the flame raises the humidity and so increases the disinfectant action of the formaldehyde. In some experiments made with this method test objects inside the fingertips of gloves were disinfected.

\section{PRECAUTIONS TO GUARD AGAINST THE TRANS- MISSION OF INFECTION BY MEANS OF FOOTWEAR.}

The floor of a room occupied by a contagious case is almost certain to be infected, as particles of secretion coughed out by the patient have been found to settle on the floor, and scales of epidermis also find their way there. Wright and Emerson ${ }^{4}$ found diphtheria bacilli on the shoes of three nurses in the diphtheria ward of the Boston City Hospital. It seems well to consider how great is the danger of contagion being spread by the feet of those leaving an infected room.

Mr. Nyhen and I havesbeen making a few simple experiments along these lines. We have put cultures of bacillus prodigiosus on different parts of the soles of our shoes, and then by means of gelatin plates, made at varying intervals, we have determined how long the bacilli would remain on the shoes while we were attending to our regular business. The growth was put on moist and also in a dry powdered form. The results of these experiments which are reported elsewhere ${ }^{5}$ may be very briefly summarized as follows:

In thirty-seven tests where the soles were inoculated and where plates were made after inter-

Wright and Emerson. Centralblatt für Bakt. 1894, xvi, 412. 5 Jour. Mass. Association of Boards of Health. Vol. xiv, No. 2, 
vals varying from one to three hours, the bacilli were found in thirteen $(35 \%)$.

In twenty-two tests with the bacilli on the under surfaces of the heels for a similar length of time, the plates were positive in twelve (55\%).

In twenty-six tests where the instep was inoculated and plates were made after intervals varying from one hour to nine days the results were positive in fifteen $(58 \%)$.

In fifteen tests with the bacilli on the lower edge of the side of the sole, eleven were positive after intervals varying from one to seventy-two hours $(73 \%)$.

These experiments show that infectious material even when dry will cling to the sole of the shoe and so may be carried long distances. It will be carried longer if, as may sometimes happen, the side of the sole or instep is infected.

It seems probable that infectious organisms are disseminated to some extent by the feet of those leaving the immediate vicinity of a contagious case, although it is not likely that disease is often spread by this means, because there are comparatively few opportunities for the infection to get from surfaces to which it may be carried by the feet to the mucous membranes of susceptible persons. There must be some danger of a physician carrying contagion in this way if he goes directly to the nursery or rooms in another house where children play on the floor.

In any case where a very strict quarantine is considered necessary, precautions should be taken to guard against infection being carried to the rest of the house by the feet of those going out from the room. These precautions are not troublesome or time-consuming. The soles of the shoes may be wet with a disinfectant on leaving the room, or overshoes may be put on before entering and taken off and left at the neutral line on leaving.

\section{A CASE OF SUSPECTED HOMICIDE PROVED TO BE SUICIDE BY STRYCHNIA.*}

BY F. J. Canedy, M.D., ShelbuRne falls, Mass.

Roland Dyer, the subject of this history, was the son of parents too shiftless to care for their own offspring, and at the age of twelve years he was bound out to a farmer in Ashfield to earn his board and clothes.

He first becomes of interest to a medico-legal society two years later, on the afternoon of Sept. 23, in a little country schoolhouse on the outskirts of the town of Ashfield, where he is kept after school and reprimanded by his teacher for conduct unbecoming a gentleman toward a girl schoolmate. He then starts for home, some distance away, in company with another boy, whom he tells while on the road that if his father (meaning Mr. Wiley, in whose family he lives) knows of this affair, he will kill him, and that he is going to commit suicide by taking strychnine. He said that he had tried it once, but had taken

* Read at the annual meeting of the Massachusetts MedicoLegal Society, June 7, 1904. too much, so that it made him sick and he threw it up.

Our next knowledge of him is from Mrs. Wiley, who says that he came in from school about five o'clock, changed his school clothes for overalls and went out to rake up rowen near the barn, Mr. Wiley being at work in the same field, some distance away, on the other side of the barn, but in sight of the boy. Mr. Wiley says that soon after the boy went to work, and before he had raked up a small cock of rowen, his twelve-yearold daughter, who had been in school that day, but not the girl connected with the punishment the boy had. received from his teacher, came out and told him what had happened at school, upon which he started to go down to speak to the boy. In doing this he passed on the other side of the barn, so that for a very short time (he thinks less than a minute) the barn was between them, and when he came out on the other side the boy had disappeared, and the next time he saw him his body was found lying in the woods three fourths of a mile away, a month later.

About two hours later, between seven and eight o'clock in the evening, Mr. Wiley appears at the office of Dr. Fessenden of Ashfield, associate medical examiner in my district, some four and a half miles from the Wiley farm, and tells his story in rather an excited manner. $\mathrm{He}$ brings with him a pewter mug having some traces of a white powder in the bottom, which he states he found under a lounge in his kitchen, and a small cork which he found lying on the kitchen floor, and he says that a small vial of strychnine which he obtained from a drug store in the spring to kill crows in the cornfield had disappeared from a shelf in the cellar way where it was kept. He further states that upon the boy's disappearance they instituted search for him, blew their dinner horn and called their neighbors to aid them, but without finding trace of him.

This Mr. Wiley was a man who had suffered some years before from some mental aberration of a melancholic type; was unpopular among his neighbors; said to have a violent temper, which often manifested itself in brutal treatment of his animals; and this boy had on several occasions received very severe punishments at his hands, although no one denied that he had been generally kindly treated in this family, and that it was only in these uncontrollable outbursts of Mr. Wiley's temper that he was liable to suffer injury. Mr. Wiley's neighbors and many of his townspeople refused to credit his version of the boy's disappearance, and openly expressed the opinion that he had killed him and secreted the body.

The state police were early called into the case, - two of them responding, - and with two deputy sheriffs a thorough search was at once instituted for the lad, chiefly under the supposition that he had been killed and his body secreted somewhere about the Wiley premises. Two or three unused wells were opened up and explored; the cellar floors of the house and barn, and wher- 